\title{
Rodeo Injuries: The Role of Safety Equipment
}

\author{
C. R. Reisenauer, J. W. Stoneback \\ University of Colorado School of Medicine, Department of Orthopedic Surgery, Aurora, Colorado
}

\author{
CORRESPONDING AUTHOR: \\ Jason W. Stoneback, \\ University of Colorado \\ Anschutz Medical Campus \\ 12631 E. 17th Ave \\ Aurora, Colorado, 80045 \\ E.mail: Jason.Stoneback@cuanschutz.edu
}

DOI:

10.32098/mltj.02.2020.05

LEVEL OF EVIDENCE: 3A

\begin{abstract}
SUMMARY
Background. Rodeo is an inherently dangerous competition and the equipment utilized to reduce the risk of injury is not well defined in the existing literature.

Methods. A systematic review of the literature published between 1990 and 2018 was conducted and combined with personal and anecdotal reports to review and assess the role that protective equipment plays in mitigating rodeo-related injuries.

Results. Studies that reported the use of protective equipment noted that helmets and protective vests prevented minor and severe trauma, though did not comprehensively limit fatal events. There was limited literature describing the usefulness of other supportive equipment used for injuries to the extremities and the neck. In studies surveying competitors, many athletes reported underuse of protective equipment due to perceived image and uncertain effectiveness.

Conclusions. Further investigation is required to quantify the impact of protective equipment as it pertains to the incidence of injury in the rodeo population.
\end{abstract}

\section{KEY WORDS}

Rodeo; injury; safety equipment; protective equipment; sports; trauma.

\section{INTRODUCTION}

The modern rodeo originated in the United States in the late 1800's with roots stemming from Spanish ranchers and the expansion of the American West (1). In 1929, rodeo was formally organized through the Rodeo Association of America, which led to the rapid expansion in popularity as a spectator sport with promising financial incentives for competitors $(1,2)$. Today, rodeo is a popular competition around the world with the strongest following in the United States, Canada, Brazil, and Australia.

The events that comprise a rodeo have varied over time, but the most common events today are well-established and can be classified into two categories: timed events and roughstock events. The timed events include barrel racing, tie-down roping, steer wrestling, and team roping. All these events involve athletes on horseback attempting to complete a task as quickly as possible. On the other side of the arena, the roughstock events are comprised of saddle bronc riding, bareback bronc riding, and bull riding. In these events, athletes attempt to ride a bucking horse or a bull for a minimum of eight seconds, after which the rider and the animal are each scored by two judges.

To meet the demands of spectators for increased entertainment and excitement in rodeo performances, animals and athletes are becoming better trained and increasingly specialized. The animals have been bred and raised to perform the necessary behaviors required in their respective rodeo events (figure 1). The most elite human competitors are now truly professional athletes with full-time focuses on competition and livelihoods relying on success throughout a yearlong season, culminating with lucrative world championships $(2,3)$. There is no doubt that today's rodeo competitions feature some of the strongest and most athletic animals and humans of all time (figure 2) (4). The increasingly fastpaced events that either join a rider and an animal together, or pit them against one another, induce an environment prime for human injury. With the growing recognition of injury patterns in sports and the need for athletes to remain healthy throughout the year, safety equipment has been gradually developed over the past 30 years with a progressive adoption by competitors.

For much of rodeo history, protective equipment was largely unused. Gloves, chaps, and cowboy boots were used out of necessity for ranchers and cowboys when working with livestock, and their use was carried over to rodeo events that simulated these activities. This equipment minimizes minor injuries and their design has remained largely unchanged over the years. It was not until July 1989 when World Cham- 
pion Bull Rider Lane Frost was fatally injured at Cheyenne Frontier Days after being gored by a bull that the need for more substantial protective equipment came into focus. Four years later, in 1993, the first protective vest for bull riding debuted, modeled after a jockey vest used in horse racing (5). Slowly, the protective vest has gained popularity in bull riding and began to cross over into the other roughstock events including bareback and saddle bronc riding. Along with the protective vest in roughstock events came the use of protective helmets; again, adopted from other sports such as hockey and lacrosse $(6,7)$. Currently, protective equipment is steadily gaining traction though the risk of injury still remains high for athletes.

Given the fast-paced and competitive nature of rodeo, and the human interaction with large livestock, there is a high risk and incidence of injuries in competitors. The various types of injuries and the associated mechanisms have been moderately documented in the literature (2,7-9). As noted in existing studies, one of the primary causes of morbidity

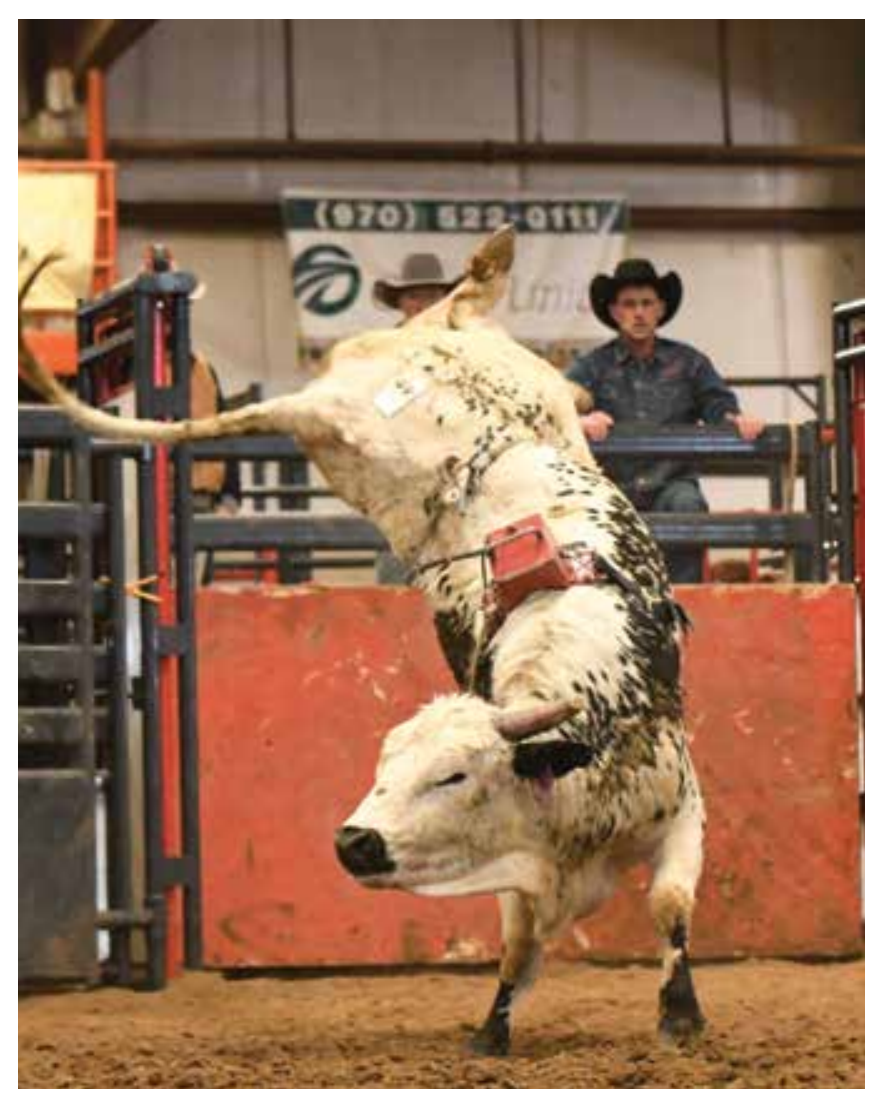

Figure 1. Bucking bull bred to buck wearing a dummy weight to simulate a rider on its back. Bulls are judged on their bucking ability to select for optimal breeding characteristics. Photo courtesy of Twisted H Bucking Bulls. and mortality in athletes is the result of equipment mishaps and unfavorable interaction with animals (2). In timed events, injury to the joints and hands are most common from dismounting running animals and rope entanglement (2). In roughstock events, the most debilitating injuries are traumatic crush injuries to the head and torso (2). Severe injury also occurs when riders are impacted against a fixed surface, such as being trampled or gored when on the ground or being crushed against the metal fences $(2,10)$. As the modern rodeo has continued to evolve, safety equipment has been further developed and recommended for use, though their implementation has been varied due to the lack of enforcement from governing bodies and lack of compliance from riders.

The primary governing organizations for adult rodeo competitors are the Professional Rodeo Cowboys Association (PRCA), Professional Bull Riders (PBR), Women's Professional Rodeo Association (WPRA), Senior Pro Rodeo (SPR), and the National Intercollegiate Rodeo Association (NIRA). Each organization regulates the general format of rodeo competitions in a similar manner, but the rules regarding the actions of the individual competitor are less clearly indicated. As a result, rules regarding the use of protective equipment are not widely mandated, and there is limited advisement from governing bodies for competitors to take necessary precautions. Only the NIRA requires a protective vest for all roughstock events with the addition of a helmet with a face mask for bull riding (11). Without mandatory-use guidelines in many competitions, athletes hold to tradition and many do not wear safety gear.

Rodeo athletes report hesitancy to adopt protective equipment due to concerns of losing their cowboy image and the associated machismo along with the limited evidence that the available protective equipment will effectively prevent harm $(11,12)$. There is also a belief and a small amount of anecdotal support that some forms of protective equipment may result in an increased risk of injury. With the uncertainty in the effectiveness of safety equipment, competitors most often adopt protective gear after experiencing an injury, rather than as a preventive measure. Improved pre-market testing of protective equipment is necessary to demonstrate the benefit of its use while meeting the needs of the athletes in their specific events. Future research is needed to understand the function of protective equipment in preventing rodeo injuries.

\section{METHODS}

A systematic review of literature was performed through a search of PubMed, Ovid, and Academic Search Premier databases using the key terms "rodeo", "injuries", "protective equipment", and "safety equipment". Studies from 
1990 to 2018 were reviewed. We aim to summarize the common types of injuries sustained in the rodeo population and describe the role that safety equipment plays in minimizing these risks to competitors.

\section{DISCUSSION}

\section{Timed Events}

Timed events generally pose a lower risk for injury due to the more controlled nature of the events and the lack of large, bucking animals. Though the incidence of injury in these events pales in comparison to the roughstock events, rodeo athletes in timed events still have the possibility of injury that can become debilitating to their lifestyle and continued competition.

\section{Barrel Racing}

Barrel racing is typically a female-only event in which a rider on horseback navigates around three large, metal barrels spread across the arena in a cloverleaf pattern. The risk for serious injury in this event is low, though collisions with barrels and falling from a horse running at full speed can pose a serious, and potentially fatal, threat to athlete safety $(2,7,10,13)$. Injury in barrel racing has been noted to occur between 1.5-1.7 times per 1000 competitor-exposures, which results in $0-3 \%$ of all rodeo injuries $(2,7,9)$.

As with most timed events in rodeo, protective equipment is generally not worn in barrel racing. Some athletes wear shin guards, either specifically designed for rodeo or adapted from soccer, to reduce the risk of lower leg injuries when contact is made with the barrel. Additional observations from the authors have been made that barrel racers often use rubber bands to secure their feet into their stirrups (figure 3). This reduces the chance that the rider would have their feet slip out of the stirrups and then lose
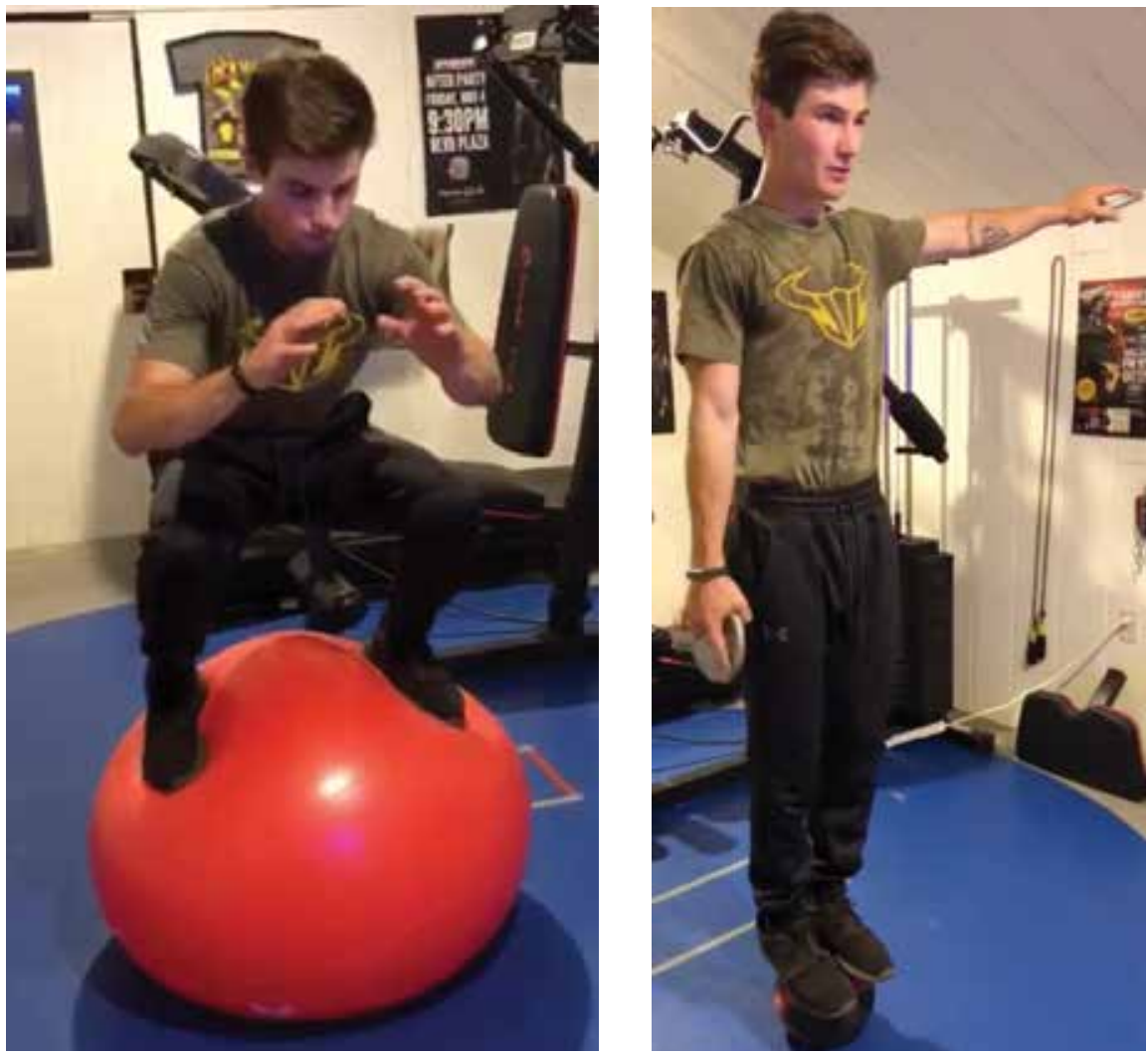

Figures $\mathbf{2 a}$ and $\mathbf{2 b}$. World Champion Bull rider Jess Lockwood performing cross training exercises to improve balance, performance, and conditioning and prevent injury. Photo courtesy of Jess Lockwood.

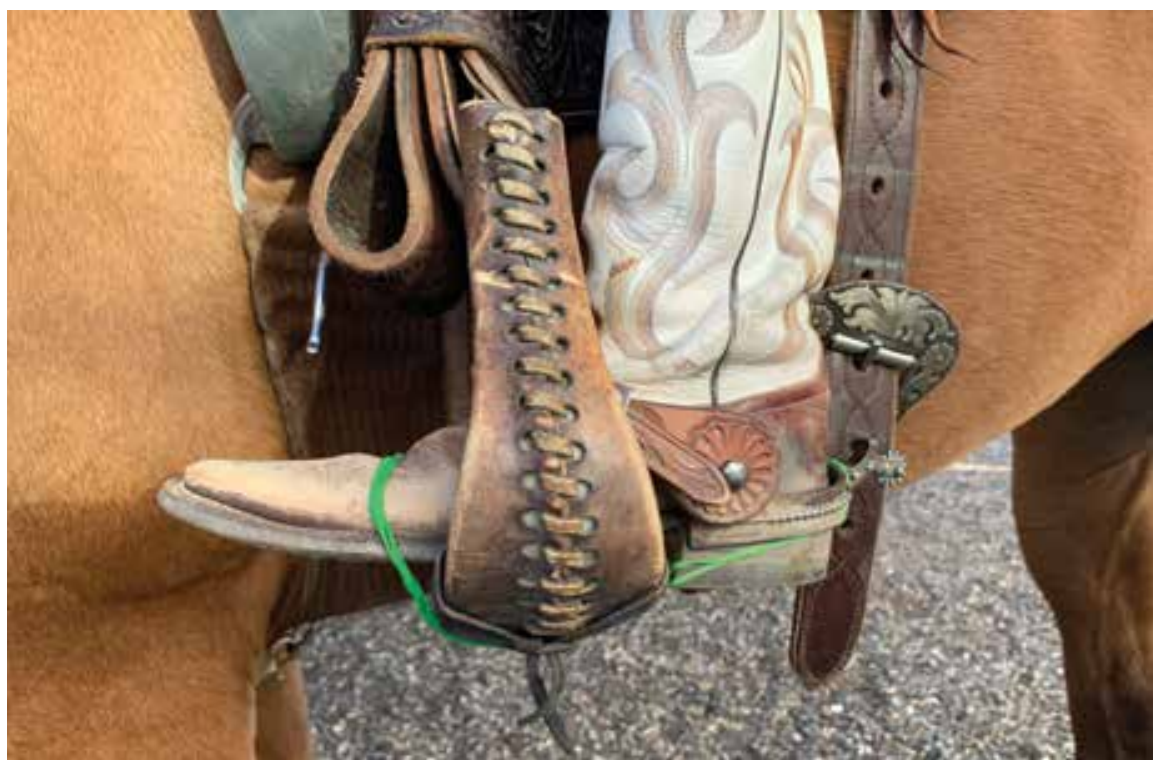

Figure 3. Barrel racer utilizing rubber bands to secure feet into stirrups. The rubber bands help prevent loss of a stirrup during competition but will break if the rider inadvertently dismounts the horse. Photo courtesy of Jason Stoneback. 
their balance in the saddle. It provides enough support to reduce the risk of an accident, while still allowing a critical release if the horse falls or the rider needs to dismount suddenly, so as to not be dragged by the horse. Helmets designed for equestrian riding have not traditionally been worn by competitors in barrel racing, though their use is increasing after being worn by a world champion-level rider at the 2014 National Finals Rodeo (14). Previous studies have noted a limited number of fatalities associated with barrel racing (7). The common mechanism for these unfortunate incidents are reported to have been an unplanned dismount in which the rider collided with another object such as the barrels or the arena fencing (2). In general, though significant injuries are a rarity in barrel racing, protective equipment is underutilized.

\section{Steer Wrestling and Tie-Down Roping}

Steer wrestling and tie-down roping are similar events in that riders start on horseback and chase a steer or a calf before dismounting their horse to physically restrain the chased animal. In steer wrestling, also referred to as bulldogging, the rider dismounts from their running horse to land directly with their arms around the steer's neck and shoulders with each hand on a horn. The competitor then wrestles the steer to the ground until it is laying on its side with all four legs facing the same direction. In contrast, during tie-down roping, also known as calf roping, the rider uses a lasso to catch a running calf around the head and then ties the lasso to the horn of their saddle. The rider then dismounts the stationary or slowing horse and ties at least three of the four legs together. The rapid dismounts from a horse and the physical manipulation of the steer or calf in both of these events are the most likely sources of injury.
The risk of fatal injury in both of these events is extremely unlikely and no deaths have been reported as a result. Though morbidity is low, competitors still experience a significant number of injuries with steer wrestling, accounting for a reported $8 \%$ of injuries and calf roping accounting for $3-12 \%$ of injuries (2). Steer wrestlers most commonly suffer from injuries to the joints as a result of landing on the animal and attempting to bring them to a stop $(2,7,9)$. Upper extremity injuries include subluxations, dislocations, and tendon ruptures, often in the shoulder, elbow, and biceps $(2,12,15)$. Injuries to the lower extremities occur most often at the knee, with anterior cruciate and medial collateral ligaments and meniscus injuries being prevalent $(2,12)$. There have also been reports of dental and maxillofacial injuries occurring after riders make unexpected contact with the horns and head of steers $(2,9)$. Previous literature reports that steer wrestlers experience approximately 52 injuries per 1000 competitor-exposures (2). Tie-down ropers also experience similar shoulder and knee injuries along with common roping injuries such as crush, degloving, and amputations when fingers or their thumb become entangled in the lasso rope $(2,9)$.

In these two events competitors do not typically utilize any prophylactic safety equipment besides their standard wear. Some may wear gloves or a mouth guard, though report of their use is limited. After experiencing a joint injury, some athletes will wear commercial braces supplemented with taping and padding (figure 4). The use of facial and dental protection should be considered along with athlete-specific braces.

\section{Team Roping}

Team roping is the only true team event in rodeo and is comprised of two competitors on horseback attempting

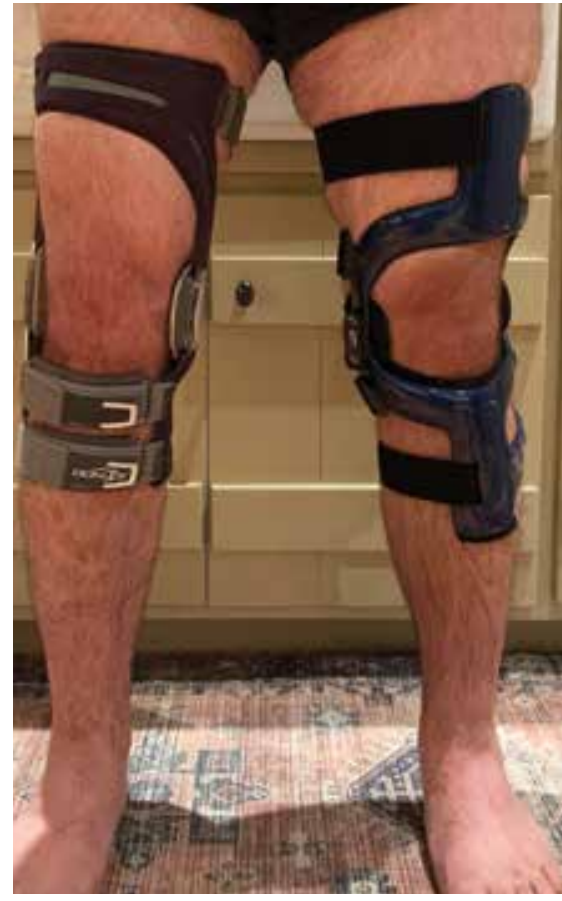

Figure 4. Five-time World Champion Steer Wrestler Luke Branquinho shows the knee braces he wears after bilateral ligamentous knee reconstructions he has required over the course of his career. Photo courtesy of Luke Branquinho.

to catch a running steer by the head and then by the back legs. The first roper, the header, uses a lasso to catch and control the steer's head and then turn the rear legs toward the second roper, the heeler, who then uses a lasso to catch the heels. The ropes on either end of the steer are tightened with both horses facing each other and the event is complete. Ropers in this event are at a low risk for mortality, though there is significant risk for damage to the hands. Other injuries are uncommon with a recent review of rodeo injuries citing that team roping comprised only $1-4 \%$ of all injuries (2).

When the roper successfully catches their respective part of the steer, they quickly wrap the trailing end of their rope around the horn of their saddle, called dallying, which is typi- 
cally covered in a rubber wrapping. The rubber on the saddle horn allows the rope to hold tight and helps prevent "running of the rope" where the rope slides and can inadvertently draw fingers into the dally (figure 5). Good rubber condition is a critical piece of safety equipment in this event. In the split second that ropers have to wrap the rope around the saddle horn, the fingers can become entrapped and athletes may experience contusions, sprains, crush injuries, degloving, and traumatic amputations $(2,9,12,16)$. The most common and severely injured digit is the thumb $(12,16)$. Though only $53 \%$ of ropers report wearing either a leather or cotton glove on their throwing hand, neither of these measures will practically reduce the risk of acute, traumatic injury to the fingers or hand $(9,16)$. A single product has been marketed to reduce the risk of thumb injury, though its effectiveness and practicality are unclear (17). Ropers must utilize extreme caution and proper technique to remain safe.

\section{Contract Personnel}

A group of individuals intrinsic to the rodeo that has gone almost entirely unreported in published literature are the contract personnel. This general term encompasses the pick-up men (a term inclusive of both male and female individuals) and the bullfighters, both of which are support staff for the rodeo in timed and roughstock events. In the timed events, they primarily assist with animal management after the roped or wrestled animals are released. In the roughstock events, contract personnel provide a more direct resource to competitors that puts them at a higher level of risk. The pick-up men assist in the bucking horse events and aid the riders off their horse in a more controlled manner. They then release the flank straps on the horse to stop the

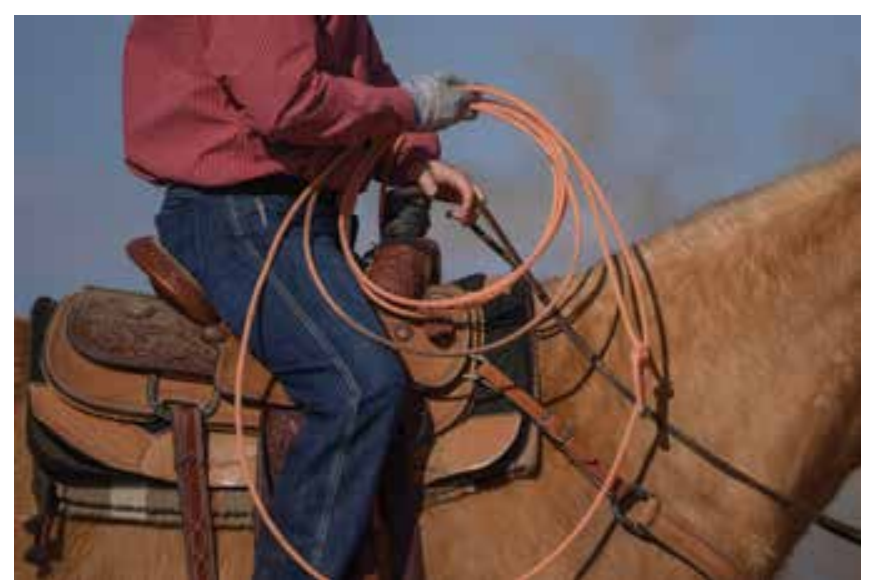

Figure 5a. Rubber around the horn of the saddle prevents the rope from sliding excessively and inadvertently pulling digits into the coils of the rope causing injury. Photo courtesy of Jason Stoneback. bucking action and direct the animal out of the arena. The most dangerous role of any of the contract personnel is the bullfighters during the bull riding event. After a successful or unsuccessful ride, the bullfighters attempt to distract the bull to avoid trampling or goring the rider and then guide the animal back to the return gate.

The pick-up men provide a supportive role to the bucking horse riders to minimize their risk of injury after a ride. At the end of the ride, the pick-up man guides his or her horse alongside the bucking horse and allows the rider to dismount and climb onto the pick-up man and his horse. Sudden movements by the bucking horse or misguided dismounts from the rider can cause injury to the pickup men. These contract personnel utilize shin guards and padded chaps to limit the injury to the lower leg as they get pinned between their horse and the bucking horse. Besides this simple measure, pick-up men utilize their experience and horsemanship to avoid personal injury.

The bullfighters are one of the most iconic images of the rodeo. Once deemed "rodeo clowns", their role has shifted and they are highly athletic individuals with intuition of a bull's behavior. These contract personnel are on foot surrounding a bull rider and quickly step in front of the bull to distract the animal once a rider dismounts. This distraction often puts the bullfighters as the target for the bull's aggression. Bullfighters are at risk of being trampled, gored, and thrown into fencing, similarly to a downed bull rider. Each bullfighter develops their own unique uniform and accompanying protective equipment. Underneath oversized, flashy clothing, the bullfighters will frequently wear padded hockey shorts, knee braces, and support tape. To increase their agility, the bullfighters forgo the standard

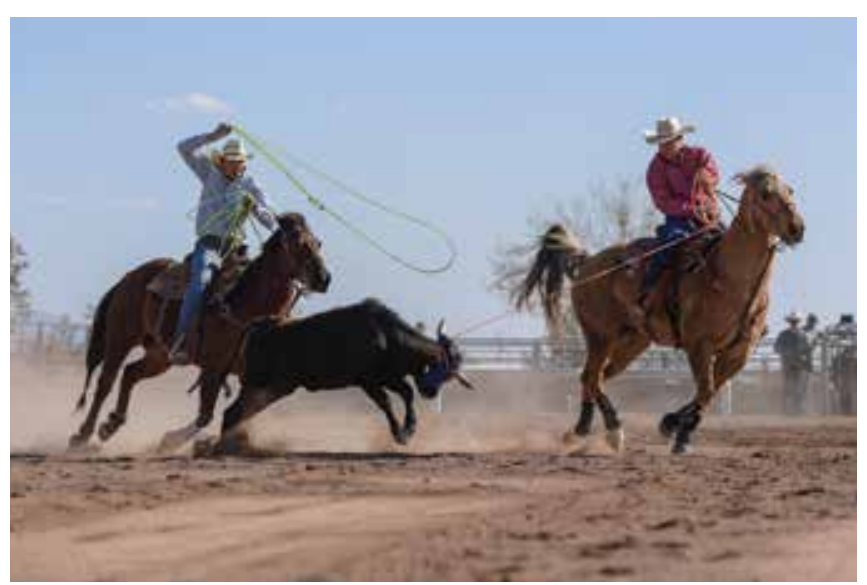

Figure 5b. The header has a secure dally allowing the steer to be turned for the heeler to rope the back legs of the steer. Photo courtesy of Jason Stoneback. 
cowboy boots and often opt for cleats intended for American football or soccer. The goal is to minimize their own personal injury while protecting the bull riders.

There is almost no existing literature on the injury rates of contract personnel in rodeo, though it is clear they are at a high risk. A single study reported that bullfighting accounted for $8 \%$ of trauma, though it is not often considered an official event $(2,18)$. These individuals have exponentially more exposure incidents with the animals compared to the riders and do not typically utilize all of the available safety equipment. Further development is necessary to create equipment that can better protect the contract personnel who perform a critical role throughout the course of a rodeo.

\section{Roughstock Events}

Roughstock events are inherently the most dangerous events in rodeo and are the most common cause of injury, with $75-87 \%$ of all injured rodeo athletes participating in one of these events $(2,7,9,11,19-21)$. The stark contrast in size between the rider and a relatively unpredictable animal warrants a high potential for unidirectional damage aimed at the athlete. The high velocity movements combined with rapid, multi-directional accelerations create forces that are highly likely to acutely injure athletes or cause longterm musculoskeletal damage. Protective equipment has been primarily developed for, and subsequently utilized in, roughstock events, though their effectiveness is still debated and is not used by all athletes.

\section{Saddle Bronc}

Saddle bronc riding is generally considered the least dangerous of the roughstock events as the riders have improved contact points and better control of the bucking horse. There are still reports of serious injury in this event and riders utilize a mix of equipment to minimize risk of injury. The major injuries in saddle bronc riding are those found in all roughstock events; riders may develop neck and back injuries from the fast, repetitive bucking of the horse and then once dismounted, the riders may get stepped on or kicked. Unique to saddle bronc riders is the occurrence of damage to the surface of the medial malleolus and anterior tibia. As the rider sets their feet forward to spur the horse's shoulders, the anterior tibia repetitively makes contact with the stirrups of the saddle, often causing bruising and/or lacerations to the anterior lower leg. As the rider spurs the animal, the medial aspect of the lower leg often comes into contact with the cantle (posterior seat) of the saddle, causing repetitive trauma to the medial malleolus. This can cause fractures and heterotopic ossification of the medial malleolus.

The saddle bronc athletes utilize a variety of protective equipment to combat the possible injuries during their ride. As the advent of the protective vest became popular in bull riding, it gained traction in bucking horse events. The protective concept is the same and the goal is to provide protection during and after dismounting the horse, primarily if the rider is thrown backwards and is kicked as the horse bucks behind itself or the rider is inadvertently stepped on by the horse. In addition, some riders may wear shin guards under their jeans to prevent stirrup injury and medial malleolus pads in their boots to prevent cantle injury. Leather chaps can have sewn-in padding to protect against bruising of the inner thighs from the saddle swells as well. Finally, saddle bronc riders wear cowboy boots with a riding heel. A riding heel is an elongated base on the boot that allows the cowboy to absorb the impact of the bronc landing on its front feet while preventing the rider's foot from slipping through the stirrup and causing the rider to become stuck in the stirrup. With this moderate level of protection, many riders will still be left bruised or lacerated from frequent, high energy impacts. In contrast to bull riding, helmets are almost entirely non-existent in saddle bronc and the relative number of head injuries is low.

Saddle bronc riders compete in what is generally considered the least dangerous roughstock event. With a more complex rigging scheme and a saddle to provide some level of support, athletes in this event are able to mitigate the incidence of injury. Due to the extra equipment, saddle bronc riders are at a unique risk of injury to the lower extremity. Further education and understanding is necessary to inform competitors on the prognosis of sustaining a head injury and need to utilize a helmet in this event.

\section{Bareback Bronc}

Bareback bronc riding poses a higher risk of injury between the two bucking horse events. With only a suitcase-style handle to maintain contact with the horse, riders experience a tremendous amount of energy transfer through a single hand and arm and are at the risk of unplanned dismounts that can lead to acute injury. Additionally, given the nature of the contact point to the horse, riders are less able to hold themselves in an upright position and repeatedly and violently swing onto the hips of the horse as it bucks, potentially leading to head and neck injury (7).

The injuries found in bareback bronc riding are both unique to this event and common to other roughstock events. With the fast, repetitive bucking motion of the horse and limited body control from the riders, the athletes frequently experience whiplash injuries to the head and neck, similar to those found in automobile accidents (12). Additionally, with the small point of contact to the horse, riders experience torquing and hyperextension injuries to the wrist, elbow, and shoulder with regular frequency (figure 6). In addition, as 


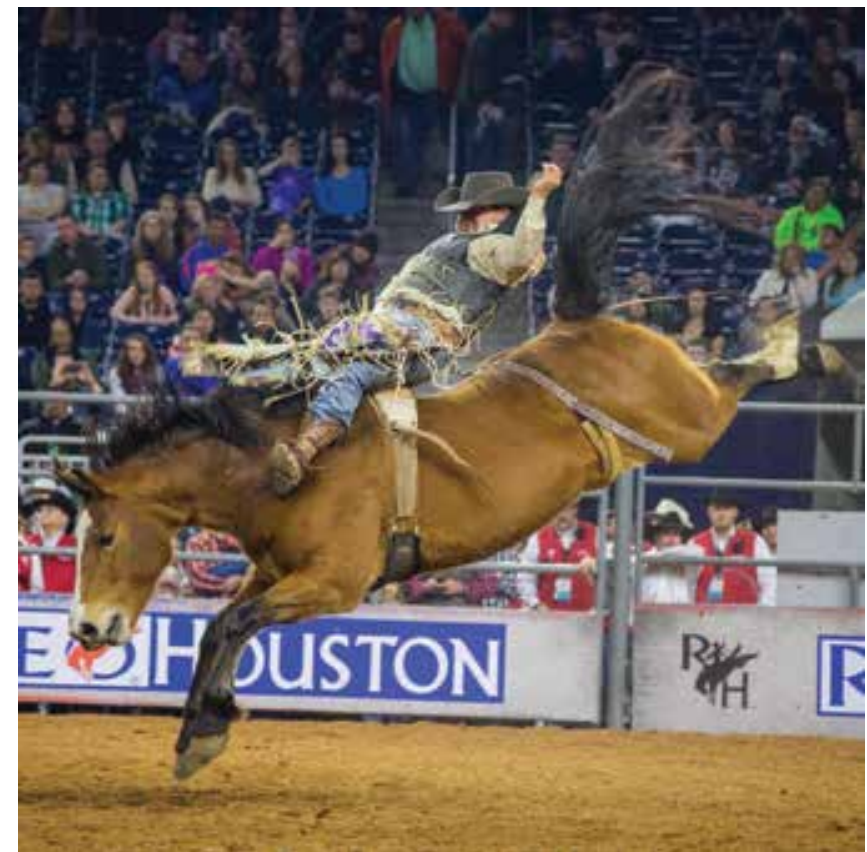

Figure 6. Bareback bronc rider during competition. Photo courtesy Scotty NeSmith.

with all roughstock events, riders are at the risk of getting kicked or trampled during an unexpected dismount.

Bareback bronc riders are at a high risk of acute injuries during their ride. To reduce the risk of injuries to the head and neck, nearly all riders will utilize a neck support that is either separate or built-in to the protective vest that is worn. This can reduce the hyperextension of the neck and avoid contact between the riders' heads and the back of the horse. Some riders may also utilize mouth guards to avoid dental injuries during this repetitive head trauma. In addition, to protect from hyperextension to the arm holding the rigging, riders may prophylactically use a commercial elbow brace or simple athletic tape for support (figure 7). At the shoulder, there is an extreme force pulling the arm in the inferior direction that can lead to subluxation or dislocation. Some riders may use tape or other supportive measures, though this is typically utilized after an injury is sustained. Most riders wear a protective vest to provide a moderate level of protection from the metal flank strap buckles that impact the rider or in the event of a high-energy impact from the horse during dismount. Limited use of protective helmets has been noted.

Riders in bareback bronc events are at a high risk of sudden, whiplash-type injuries. Further investigation is needed to better protect the wrist, elbow, and shoulder from injury during this event. Additionally, further study is required to determine if helmet use would prevent concussion or if helmet use may increase injury rates from the increased weight of the riders head.

\section{Bull Riding}

Bull riding has been notoriously deemed, "the most dangerous eight seconds in sports", due to the high incidence of severe injury with $28-50 \%$ of all rodeo injuries coming from this event $(2,6,8,19)$. The bull may easily outweigh the rider ten-fold and is prone to aggressive behavior. With only a tightly wrapped rope to secure the rider's hand to the bull, it is easy for the rider to lose control and have serious injury during the ride and during dismount. Furthermore, athletes who successfully ride for the minimum eight seconds are required to dismount to the ground, opposed to a pick-up man in bucking horse events, which can lead to injury. In agreement with general perception, there is strong evidence that bull riding is by far the most dangerous rodeo event overall.

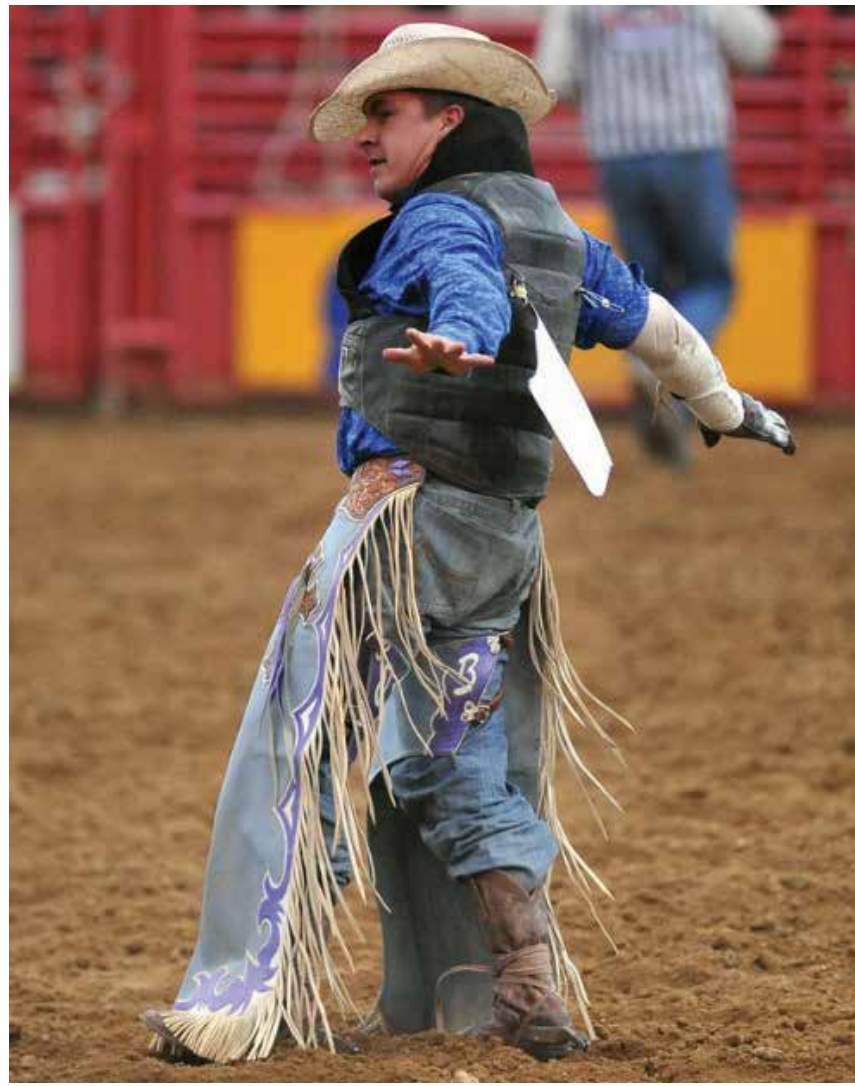

Figure 7. Bareback rider after a ride and dismount in the arena. Note the large neck roll to help prevent hyperextension injury of the neck and prophylactically taped right riding elbow to prevent hyperextension of the elbow during the ride. Photo courtesy of Scotty NeSmith. 
Competitors in bull riding can experience injuries similar to those in unrestrained vehicle crashes as well as an entire gamut of orthopedic injuries. Before the ride even begins, riders in the chute are at risk of the bull becoming agitated and bucking, which can lead to lower extremities being pinned against the bucking chutes or the rider getting thrown into, off, or under the bull. Once the ride begins, the only connection to the bull is through a suitcase-style handle and rope held in a single hand. The fast spinning and bucking nature of the bull causes riders to slide laterally while being thrown anteriorly and posteriorly on the bull. Severe head trauma can occur if contact is made with the bull's head or horns, as it has been observed that injuries to the head and neck account for $27 \%$ of all bull riding injuries (8). Riders also experience injury to the hand, wrist, elbow, and shoulder of the arm holding the bull rope. Once the ride is over, the riders are at the greatest risk for life-threatening injury. Riders can get "hung up", which is a term that describes an incident in which the rider cannot remove their hand from the rope around the bull. This often results in the rider being dragged by the bull and often falling underneath the animal as it stomps. As the rider dismounts the bull completely, if they land underneath or in the path of the bull, they are at risk of being trampled and crushed by the bull. The aggressive bull is also prone to goring competitors with its horns as they attempt to escape after dismount. Being trampled or gored may lead to traumatic injury to the chest, abdomen, and pelvis which are the leading causes of death in roughstock events (2).

Bull riders are typically the most protected athletes in the rodeo, though they still experience the highest rate of morbidity and mortality with $92.5 \%$ of surveyed riders responding that they have experienced an injury in their career $(8,11,19)$. After polarizing deaths to rodeo riders years ago, protective vests and helmets have come in to popularity with reports that $95 \%$ of bull riders always wear vests (11). The helmet and vest provide adequate protection during the ride and during dismount if the athletes are kicked, but they often do little to stop the crush injuries that occur if a rider is trampled or gored while on the ground or pinned into the metal fencing (figure 8) $(2,7)$. While vests are utilized by nearly all riders, helmet use is split due to the incidence of secondary injuries (7) and the belief that helmets impair riding ability, with only $31 \%$ of bull riders reporting to always wear a helmet $(7,11)$. One example of a secondary injury sustained through the use of a helmet that has been noted by the senior author is traumatic ear lacerations and avulsions as a result of the helmet moving during impact. The proposed mechanism for this is that a torsional force occurs when a rider's helmet is violently impacted on a bull's head or horns. The helmet rotates circumferentially on the riders head and the ear is avulsed by the cutouts in the helmet surrounding the ear. Furthermore, inconsistent use of helmets is driven by athlete perception, as it has been noted that $17 \%$ of riders report that helmets restrict vision and $14 \%$ report they affect their general riding ability (11). Most helmets had been adopted from other contact sports such as hockey and lacrosse, but with the introduction of a rodeo-specific helmet, the Bull Tough Helmet, athlete perception may be altered (22). Most athletes (61\%) in this event are also utilizing mouth guards to decrease the incidence of preventable dental injuries (11). Support for the wrist, elbow, and shoulder are often achieved through the use of commercial braces and athlete-specific taping regiments, though the use of this equipment is rarely overseen by a medical professional and is primarily used by riders who have experienced a previous injury.

There is still much to be learned about the effectiveness of protective equipment in bull riding. Further design and development is necessary to create helmets and vests that can better resist acute traumatic injury, while also allowing

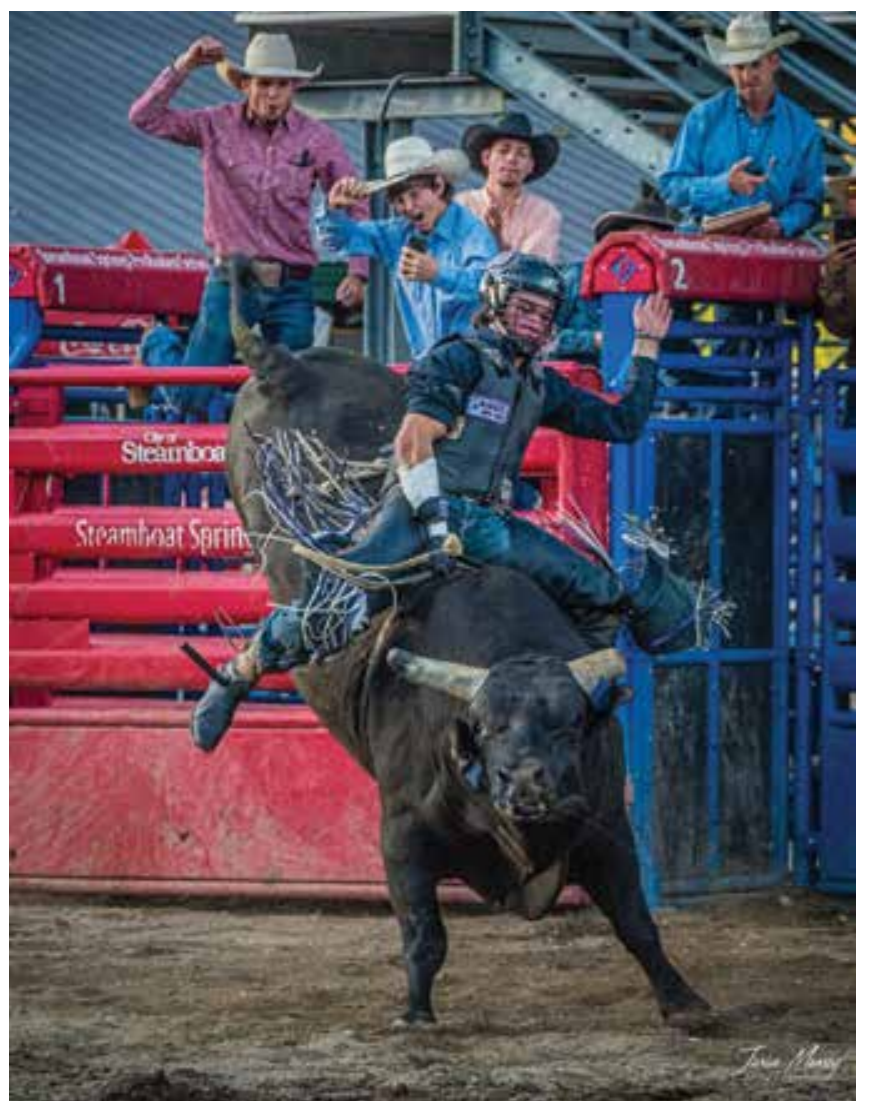

Figure 8. Bull rider during competition. Note the use of protective vest and helmet with faceguard. Photo courtesy of Colton Fritzlan. 
the rider to maintain their physical function required to ride a bull successfully. Until that time, riders should consider utilizing the available equipment to reduce the risk of other preventable injury.

\section{CONCLUSIONS}

Rodeo is an inherently dangerous and injury-prone sport that has a history deeply rooted in cowboy culture. Though sports medicine has continued to evolve in this environment, the attitudes and beliefs of riders and spectators adversely support the use of protective equipment. To complicate this philosophy, the effectiveness of the various forms of safety equipment available is still uncertain. Though it is not definitively proven, the prevailing literature suggests that the use

\section{REFERENCES}

1. Meyers MC, Laurent Jr CM. The Rodeo Athlete- Sports Science: Part 1. Sports Med. 2010;40(5):417-431.

2. Meyers MC, Laurent Jr CM. The Rodeo Athlete- Injuries: Part II. Sports Med. 2010;40(10):817-839.

3. Sinclair AJ, Ransone JW. Physical activity and its relationship to rodeo injury and success. Journal of Strength and Conditioning Research. 2004;18(4):873-877.

4. Brandenburg MA, Schmidt A, Mallonee S. Bull-riding injureis. Annals of Emergency Medicine. 1998;32(1):118.

5. Lavinge P. Rodeo vests: Adequate safety devices? 2011; https:// www.espn.com/espn/otl/news/story?id=6674104, 2019.

6. Livingston R, Koval L, Livingston L, Scholes N. Six-year retrospective study of bull-riding injuries in central Queensland. Australas Med J. 2012;5(7):362-366.

7. Butterwick DJ, Hagel B, Nelson DS, LeFave MR, Meeuwisse WH. Epidemiologic Analysis of Injury in Five Years of Canadian Professional Rodeo. The American Journal of Sports Medicine. 2002;30(2):193-198.

8. Butterwick DJ, Meeuwisse WH. Bull Riding Injuries in Professional Rodeo. The Physician and Sportsmedicine. 2015;31(6):37-41.

9. Meyers MC, Elledge JR, Sterling JC, Tolson H. Injuries in intercollegiate rodeo athletes. The American Journal of Sports Medicine. 1990;18(1):87-91.

10. Butterwick DJ, Lafave MR, Lau BH, Freeman T. Rodeo Catastrophic Injuries and Registry: Initial Retrospective and Prospective Report. Clinical Journal of Sport Medicine. 2011;21(3):243-248.

11. Ross DS, Ferguson A, Bosha P, Cassas K. Factors that Prevent Roughstock Rodeo Athletes from Wearing Protective Equipment. Current Sports Medicine Reports. 2010;9(6):342-346. of modern protective equipment can reduce the risk of injury and lead to fewer debilitating or fatal injuries (11).

Additional research, development, and testing is necessary to develop protective equipment that can withstand the unique high energy exposures that rodeo athletes encounter while providing the freedom of movement these athletes need to be successful. There is need for biomechanical research to quantify the forces involved in acute injuries and need for epidemiological studies to establish the role that safety equipment plays in reducing the incidence of injury in rodeo athletes.

\section{CONFLICT OF INTERESTS}

The authors declare that they have no conflict of interests.

12. Downey DJ. Rodeo Injuries and Prevention. Current Sports Medicine Reports. 2007;6:328-332.

13. Thomas KE, Annest JL, Gilchrist J, Bixby-Hammett DM. Non-fatal horse related injuries treated in emergency departments in the United States, 2001-2003. Br J Sports Med. 2006;40(7):619-626.

14. Kovatch K. Fallon Taylor is Taking Las Vegas... In a Helmet. 2014; https://www.horsenation.com/2014/12/09/fallon-taylor-is-taking-las-vegas-in-a-helmet/, 2019.

15. Lau BH, Butterwick DJ, Lafave MR, Mohtadi NG. Retrospective review of pectoralis major ruptures in rodeo steer wrestlers. Adv Orthop. 2013;2013:987910.

16. Moneim MS, Firoozbakhsh K, Gross D, Young SD, Omer G. Thumb Amputations from Team Roping. The American Journal of Sports Medicine. 2003;31(5):728-735.

17. The Bulldog Thumb Protector. 2017; http://www.bulldogthumbprotector.com/The-Bulldog.html.

18. Griffin R, Peterson K, Halseth J. Injuries in Professional Rodeo. Phys Sportsmed. 1983;11(8):110-116.

19. Brandenburg MA, Butterwick DJ, Hiemstra LA, Nebergall $\mathrm{R}$, Laird J. A comparison of injury rates in organized sports with special emphasis on American bull riding. International SportMed Journal. 2007;8(2):77-86.

20. Butterwick DJ, Meeuwisse WH. Effect of Experience on Rodeo Injury. Clinical Journal of Sport Medicine. 2001;12(1):30-35.

21. Meyers MC, Sterling JC, Souryal TO. Radiographic findings of the upper extremity in collegiate rodeo athletes. Med Sci Sports Exerc. 2003;35(4):543-547.

22. Brandenburg MA, Archer P. Mechanisms of Head Injury in Bull Riders with and without the Bull Tough Helmet- A Case Series. J Okla State Med Assoc. 2005;98(12):591-595. 